\title{
Airway Mechanosensor Behavior during Application of Positive End-Expiratory Pressure
}

\author{
Juan Guardiola ${ }^{a}$ b Bryan Moffett $^{a}$ Huafeng $\mathrm{Li}^{\mathrm{b}}$ Rajeesh Punnakkattu ${ }^{\mathrm{b}}$ \\ Bogden Moldoveanu ${ }^{a, b}$ Jun Liu ${ }^{a, b} \quad$ Lei Du $^{b}$ Jerry $\mathrm{Yu}^{\mathrm{a}, \mathrm{b}}$ \\ ${ }^{a}$ Robley Rex VA Medical Center, and ${ }^{b}$ Pulmonary Medicine, University of Louisville, Louisville, Ky., USA
}

\section{Key Words}

Cellular mechanotransduction · Mechanosensors · Positive pressure respiration $\cdot$ Sensory receptors $\cdot$ Vagal afferents

\begin{abstract}
Background: Positive end-expiratory pressure (PEEP) is commonly used in clinical settings. It is expected to affect the input from slowly adapting pulmonary stretch receptors (SARs), leading to altered cardiopulmonary functions. However, we know little about how SARs behave during PEEP application. Objectives: Our study aimed to characterize the behavior of SARs during PEEP application. Methods: We recorded single-unit activities from 18 SARs in the cervical vagus nerve and examined their response to an increase of PEEP from 3 to $10 \mathrm{~cm} \mathrm{H}_{2} \mathrm{O}$ for 20 min in anesthetized, openchest and mechanically ventilated rabbits. Results: The mean activity of the units increased immediately from 35.7 to 80.5 impulses per second at the fifth breath after increasing PEEP $(n=14, p<0.001)$ and then gradually returned to 56.5 impulses per second at the end of 20 min of PEEP application $(p<0.001)$. In the meantime, peak airway pressure increased from 9.3 to $32.7 \mathrm{~cm} \mathrm{H}_{2} \mathrm{O}$, and then gradually returned to $29.4 \mathrm{~cm} \mathrm{H}_{2} \mathrm{O}(\mathrm{n}=18 ; \mathrm{p}<0.05)$ after $20 \mathrm{~min}$. The remaining four units ceased firing at $34.7 \mathrm{~s}$ (range 10-56 s)
\end{abstract}

after their initial increased activity upon $10 \mathrm{~cm} \mathrm{H}_{2} \mathrm{O}$ PEEP application. The unit activity resumed as the PEEP was returned to $3 \mathrm{~cm} \mathrm{H}_{2} \mathrm{O}$. Conclusions: High PEEP stimulates SARs and SAR activity gradually returns towards the baseline via multiple mechanisms including receptor deactivation, neural habituation and mechanical adaptation. Understanding of the sensory inputs during PEEP application will assist in developing better strategies of mechanical ventilation.

(c) 2014 S. Karger AG, Basel

\section{Background}

Airway sensory receptors play an important role in the control of breathing and airway caliber [1-3]. The activation of airway mechanosensors (mechanoreceptors) called slowly adapting pulmonary stretch receptors (SARs) - initiates the Hering-Breuer reflex (HBR) [4], through which signals are sent to the central nervous system to trigger expiration. Positive end-expiratory pressure (PEEP) is commonly applied during mechanical ventilation in critically ill patients and during noninvasive mechanical ventilation using either bilevel positive airway pressure (BPAP) or continuous positive airway pressure (CPAP) $[5,6]$. In acute respiratory distress syn-

\section{KARGER}

E-Mail karger@karger.com

www.karger.com/res
C 2014 S. Karger AG, Basel

0025-7931/14/0884-0339\$39.50/0
Prof. Dr. Jerry Yu

Pulmonary Division, Department of Medicine

University of Louisville

ACB-3, 550 S. Jackson St., Louisville, KY 40292 (USA)

E-Mail j0yu0001@ louisville.edu 
drome, a high PEEP is employed to recruit collapsed alveoli in dependent regions of the lung to improve V/Q mismatch [7]. PEEP is also used in spontaneous breathing trials during ventilator weaning and in obstructive sleep apnea. Tryfon et al. [8] applied PEEP to healthy subjects and patients with chronic obstructive pulmonary disease (COPD) or interstitial fibrosis, and examined the HBR. The HBR was augmented in interstitial fibrosis (decreased lung compliance), but was unaffected in COPD (chronic intrinsic PEEP), even at a PEEP level of $20 \mathrm{~cm}$ $\mathrm{H}_{2} \mathrm{O}$ [8]. In 1975, Stanley et al. [9] demonstrated that phrenic nerve activity was inhibited by application of a $10-\mathrm{cm} \mathrm{H}_{2} \mathrm{O}$ PEEP, which was independent of blood gases. The inhibition rebounded immediately as the PEEP was removed. Expiratory time also increased as the PEEP level increased; however, with continued PEEP, the expiratory time returned towards baseline [10]. Despite the frequent use of PEEP in clinical practice, little is known about the neurophysiological effects of high PEEP, particularly its interactions with SARs. The purpose of this study was to elucidate the effects of PEEP on SAR discharge, which may be critical in the control of breathing.

\section{Materials and Methods}

\section{General}

All procedures complied with the ethical standards established by the National Institutes of Health and were approved by the internal Animal Use and Care Committee of the University of Louisville. Ky., USA. Fifteen New Zealand White male rabbits (2.0-2.3 $\mathrm{kg}$ ) were anesthetized with $20 \%$ urethane $(1 \mathrm{~g} / \mathrm{kg}$, i.v., Sigma-Aldrich, St. Louis, Mo., USA). After midline incision to expose the trachea and vagus nerve, the trachea was cannulated low in the neck. The lungs were ventilated at $10 \mathrm{ml} / \mathrm{kg}$ tidal volume with a rate of 30 cycles/min by a Harvard ventilator (Model 683, South Natick, Mass., USA), maintaining PEEP by placing the expiratory outlet under $3 \mathrm{~cm} \mathrm{H}_{2} \mathrm{O}$. Airway pressure was monitored by a Statham pressure transducer (P23) attached to the tracheal tube. The chest was then opened wide along the midline so that the receptive field could be located by gently exploring the pleural lung surface with a cotton tip. Receptor responses to cyclic changes in airway pressure and PEEP were examined. Airway pressure and afferent activities were recorded by an Astro-Med thermorecorder (Dash IV), recording SAR single-unit activities and responses to increasing PEEP from 3 to $10 \mathrm{~cm} \mathrm{H}_{2} \mathrm{O}$ over a course of $20 \mathrm{~min}$.

\section{Recording Afferent Activity}

SAR receptive fields were identified in the peripheral lung by recording single-unit activities from the cervical vagus nerve using conventional methods $[11,12]$. The vagus nerve (either right or left) was separated from the carotid sheath, placed on a dissecting platform and covered with mineral oil. A small afferent bundle was cut from the caudal end of the vagus nerve, leaving the main trunk intact to continue to propagate afferent signals. This afferent bun-
Table 1. Categorization of SARs and their response to PEEP

\begin{tabular}{llcc}
\hline SAR type & Deactivation & Nondeactivation & Total \\
\hline High-threshold & 1 & 10 & 11 \\
Low-threshold & 3 & 4 & 7 \\
Total & 4 & 14 & 18
\end{tabular}

High-threshold SARs are those discharged only during the lung inflation phase. Low-threshold SARs are those discharged continuously throughout the ventilatory cycle, i.e. during both the lung inflation and deflation phases. Although not statistically significant, the trend indicates that low-threshold SARs are more easily deactivated.

dle was dissected with two pairs of fine forceps into thin filaments, which were then separated into finer filaments and were placed on an electrode to record single-unit action potentials. The electrodes were connected to a high-impedance probe (model HIP511) from which the output was led to a Grass (P511) amplifier. After suitable amplification, the single-unit activities were displayed on an oscilloscope, and acoustically monitored by an attached loudspeaker. In addition, a voltage analog of impulse frequency was produced by a rate-meter (Frederick Haer, Brunswick, Maine, USA) at a bin width of $0.1 \mathrm{~s}$.

Baseline unit activity was calculated for three ventilator cycles prior to raising PEEP in each rabbit, and served as its own control (measured in impulses per second, imp/s). Peak response was obtained over three ventilator cycles following the application of 10 $\mathrm{cm} \mathrm{H}_{2} \mathrm{O}$ PEEP after airway pressure reached maximum. The activity at the end of PEEP maneuver was calculated for the three ventilator cycles prior to reducing PEEP to $3 \mathrm{~cm} \mathrm{H}_{2} \mathrm{O}$. Mean activity over three respiratory cycles as well as the maximum and minimum activity were determined for each single unit (expressed as $\mathrm{imp} / \mathrm{s})$.

\section{Statistical Analysis}

Data were analyzed by statistical software (STATA version 11, StataCorp LP, Tex., USA). Continuous variables were analyzed with the two-sample t test. A p value $<0.05$ was considered significant.

\section{Results}

Eighteen SARs were recorded, 7 low-threshold and 11 high-threshold SARs (table 1). Fourteen continuously discharged while the other 4 suddenly stopped their discharge during the 20 -min $10 \mathrm{~cm} \mathrm{H}_{2} \mathrm{O}$ PEEP application. Figure 1 shows a typical SAR recording in 14/18 units (77\%). The tracing begins with the rabbit ventilated at $3 \mathrm{~cm} \mathrm{H}_{2} \mathrm{O}$ PEEP for 4 breaths followed by elevation of the PEEP to $10 \mathrm{~cm} \mathrm{H}_{2} \mathrm{O}$. This resulted in an immediate in- 


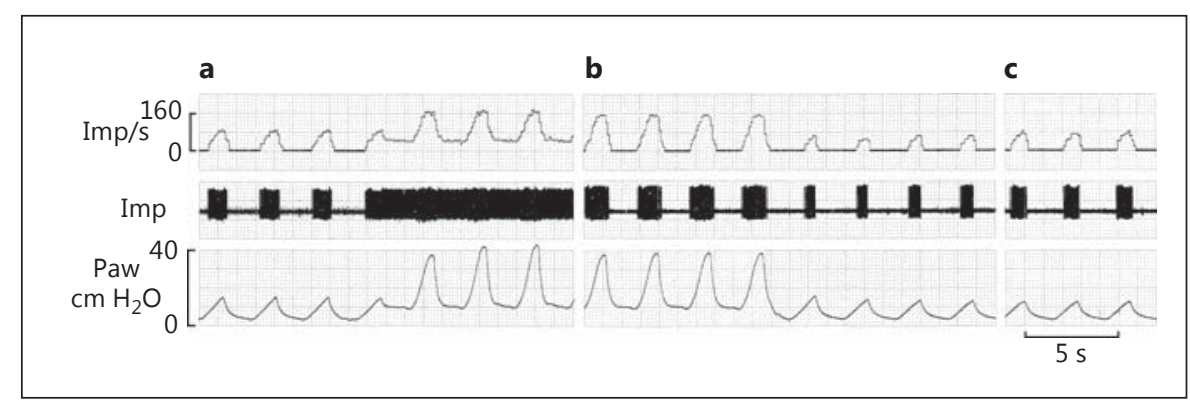

Fig. 1. A typical SAR, recorded from the left cervical vagus nerve in an anesthetized, open-chest and mechanically ventilated rabbit. The tracings are unit activity expressed as imp/s, unit activity (Imp), and airway pressure (Paw). The rabbit was ventilated with a PEEP of $3 \mathrm{~cm} \mathrm{H}_{2} \mathrm{O}$. a PEEP was then increased to $10 \mathrm{~cm} \mathrm{H}_{2} \mathrm{O}$. Increasing PEEP from 3 to $10 \mathrm{~cm} \mathrm{H}_{2} \mathrm{O}$ significantly increased the airway pressure swing and the SAR discharged continually at the beginning. The time lapse from $\mathbf{a}$ to $\mathbf{b}$ and $\mathbf{b}$ to $\mathbf{c}$ was $20 \mathrm{~min}$ and $1 \mathrm{~min}$, respectively. At the end of the 20-min hyperinflation, the SAR discharged intermittently as a typical high-threshold SAR. b Peak activity was sustained. c Upon returning the PEEP to $3 \mathrm{~cm}$ $\mathrm{H}_{2} \mathrm{O}$, the SAR discharged significantly less than at baseline, and after $1 \mathrm{~min}$, it had almost recovered. This represents 14/18 SARs tested.
Fig. 2. A typical SAR that deactivated during $30 \mathrm{~cm} \mathrm{H}_{2} \mathrm{O}$ constant pressure inflation and also during $10 \mathrm{~cm} \mathrm{H}_{2} \mathrm{O}$ PEEP application with cyclic ventilation. a Unit activity (Imp) ceased during lung deflation with a negative pressure. $\mathbf{b}$, c Lung inflation at a constant positive pressure of 10 and $30 \mathrm{~cm}$ $\mathrm{H}_{2} \mathrm{O}$, respectively. d SAR activity during application of $10 \mathrm{~cm} \mathrm{H}_{2} \mathrm{O}$ PEEP (i.e. during intermittent positive pressure ventilation). The unit resumed its activity shortly after returning of the airway pressure (Paw) to the normal level. This represents $4 / 18$ SARs tested.

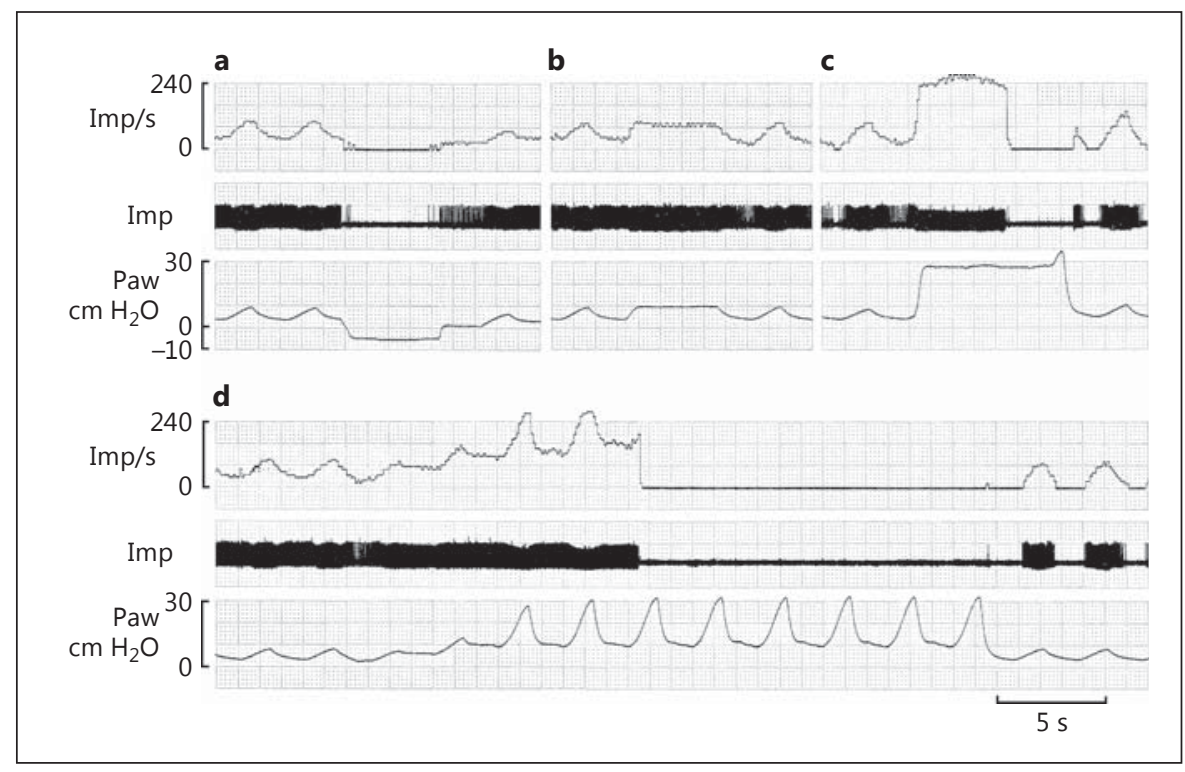

crease in mean activity from $35.7 \pm 4.2$ to $80.5 \pm 7.3 \mathrm{imp} / \mathrm{s}$ $(\mathrm{n}=14, \mathrm{p}<0.01)$, reaching a $125 \%$ increase in discharge (table 2). However, over the course of $20 \mathrm{~min}$ of $10 \mathrm{~cm}$ $\mathrm{H}_{2} \mathrm{O}$ PEEP, the activity decreased, reaching a low new level $(56.5 \pm 5.7 \mathrm{imp} / \mathrm{s}, \mathrm{n}=14, \mathrm{p}<0.01)$ that was still $58 \%$ above the baseline, a $30 \%$ decrease from the initial measurement after application of PEEP. Similarly, the maximum and minimum discharge activities were also increased by $62.8 \%(\mathrm{p}<0.001)$ and $462.4 \%(\mathrm{p}<0.001)$ initially following the $10 \mathrm{~cm} \mathrm{H}_{2} \mathrm{O}$ PEEP application. After 20 min, these maximum and minimum discharge rates were still elevated but decreased to 40.7 and $160 \%$ above the baseline. Upon returning PEEP to $3 \mathrm{~cm} \mathrm{H}_{2} \mathrm{O}$, the activity diminished below the control and then gradually recovered to the control level within $1 \mathrm{~min}$ (fig. 1).

There was different behavior in $4 / 18$ units (22\%), with an abrupt cessation of activity. Three were lowthreshold (75\%) and 1 was a high-threshold SAR (25\%). They had an initial surge of receptor activity after $10 \mathrm{~cm}$ $\mathrm{H}_{2} \mathrm{O}$ PEEP application similar to that seen in figure 1, which was followed by an abrupt termination of discharges (fig. 2) at a mean duration of $34.7 \mathrm{~s}$ (range 10$56 \mathrm{~s}$ ). These deactivated units could be reactivated by lowering the inflation pressure and deactivated again by 
Table 2. SAR activity in response to $10 \mathrm{~cm} \mathrm{H}_{2} \mathrm{O}$ PEEP application

\begin{tabular}{|c|c|c|c|c|}
\hline & $\begin{array}{l}\text { SAR activity, } \\
\mathrm{imp} / \mathrm{s}\end{array}$ & Control & $\begin{array}{l}\text { Start }^{\mathrm{a}} \text { of } \\
\text { PEEP }\end{array}$ & $\begin{array}{l}\text { End }^{\mathrm{b}} \text { of } \\
\text { PEEP }\end{array}$ \\
\hline \multirow{3}{*}{$\begin{array}{l}\text { Group 1 } \\
(\mathrm{n}=14)\end{array}$} & Mear & $35.7 \pm 4.2$ & $80.5 \pm 7.3$ & $56.5 \pm 5.7$ \\
\hline & Maximum & $84.2 \pm 5.2$ & $137.1 \pm 11.4$ & $118.5 \pm 9.3$ \\
\hline & Minimum & $8.5 \pm 3.7$ & $47.8 \pm 6.2$ & $22.1 \pm 4.9$ \\
\hline \multirow{3}{*}{$\begin{array}{l}\text { Group } 2 \\
(\mathrm{n}=18)\end{array}$} & $\mathrm{Mer}$ & $35.5 \pm 3.5$ & $86.2 \pm 7.1$ & $44.0 \pm 7.2$ \\
\hline & Maximum & $82.2 \pm 4.4$ & $142.2 \pm 9.5$ & $92.2 \pm 13.9$ \\
\hline & Minimum & $7.2 \pm 3.0$ & $52.2 \pm 6.1$ & $17.2 \pm 4.4$ \\
\hline
\end{tabular}

Mean activity was averaged over three respiratory cycles; maximum (minimum) activity is the highest (lowest) discharge frequency during $0.1 \mathrm{~s}$ within a cycle. The differences are significant between baseline and the start of PEEP $(p<0.01)$ and between the start of PEEP and the end of PEEP $(\mathrm{p}<0.01)$ in both groups. Group 1: deactivated SARs removed. Group 2: all SARs.

a At the fifth ventilator cycle of the application of PEEP. ${ }^{\mathrm{b}}$ At the fifth ventilator cycle before ending the PEEP application.

Table 3. Peak airway pressure during $10 \mathrm{~cm} \mathrm{H}_{2} \mathrm{O}$ PEEP application

\begin{tabular}{llcc}
\hline & Control & Start $^{\mathrm{a}}$ of PEEP & End $^{\mathrm{b}}$ of PEEP \\
\hline Mean, $\mathrm{cm} \mathrm{H}_{2} \mathrm{O}$ & 9.3 & 32.7 & 29.4 \\
$\mathrm{SD}, \mathrm{cm} \mathrm{H} \mathrm{H}_{2} \mathrm{O}$ & 1.3 & 7.6 & 5.1 \\
$\mathrm{SE}, \mathrm{cm} \mathrm{H} \mathrm{H}_{2} \mathrm{O}$ & 0.31 & 1.8 & 1.2 \\
\hline
\end{tabular}

The difference in peak airway pressure is statistically significant $(\mathrm{n}=18 ; \mathrm{p}<0.01$ between control and start of PEEP; $\mathrm{p}<0.05$ between start and end of PEEP).

a, b Same as in table 2.

returning to the high pressure. Activation and deactivation occurred abruptly, with unit activity oscillating between high frequencies and zero. These 4 units became deactivated at a constant pressure inflation of $30 \mathrm{~cm}$ $\mathrm{H}_{2} \mathrm{O}$ but not at $10 \mathrm{~cm} \mathrm{H}_{2} \mathrm{O}$ (fig. 2).

During the course of $10 \mathrm{~cm} \mathrm{H}_{2} \mathrm{O}$ PEEP application, peak airway pressure increased initially, and then decreased gradually. Although this change was small (3.3 $\mathrm{cm} \mathrm{H}_{2} \mathrm{O}$ ), it was statistically significant (fig. 1; table 3).

\section{Discussion}

Our data demonstrate a dichotomous SAR response during $20 \mathrm{~min}$ of $10 \mathrm{~cm} \mathrm{H}_{2} \mathrm{O}$ PEEP application. Four SARs deactivated after applying PEEP; in 14, the activity increased initially and then declined gradually to a steady state above the baseline. In the meantime, the airway pressure also decreased to an extent that was small but statistically significant. This suggests multiple mechanisms including receptor deactivation, mechanical adaptation and neural habituation for downregulating SAR activity during continuous PEEP.

Deactivation of SARs has been reported following lung hyperinflation under a constant pressure in rabbits [13], cats [14] and opossums [15]. Deactivation also occurs after injecting ouabain, an inhibitor of $\mathrm{Na}^{+} / \mathrm{K}^{+}$-ATPase, into a vein [16] or directly into the receptive field [17]. Our study demonstrates that SARs can be deactivated under high cyclic airway pressure (induced by PEEP). It is possible that deactivation is due to a deficiency of $\mathrm{Na}^{+}$/ $\mathrm{K}^{+}$-ATPase from metabolic stresses or depletion [13]. The majority (75\%) of the deactivated SARs were lowthreshold SARs. This is consistent with previous reports that SARs with a high discharge frequency are more susceptible to deactivation $[13,15]$. Since low-threshold SARs fire continuously throughout the respiratory phase [1], they are more metabolically active. Similarly, some arterial baroreceptors are stimulated and then deactivated after bolus injection of phenylephrine to increase blood pressure [18]. This mechanism of deactivation thus seems to be universal across mechanosensors.

The activity of the 4 deactivated units ceased shortly after applying $30 \mathrm{~cm} \mathrm{H}_{2} \mathrm{O}$ constant pressure but not with $10 \mathrm{~cm} \mathrm{H}_{2} \mathrm{O}$ (fig. 2). This implies that the increased airway pressure secondary to PEEP, but not the PEEP itself, was responsible for SAR deactivation. Therefore, airway pressure is an important determinant of the SAR behavior. Airway pressure declined during high PEEP application (fig. 1; table 3). This may result from recruitment of previously collapsed lung units [7], causing air redistribution and pressure reduction. Such pressure-reduction-induced decrease in SAR activity is referred to as mechanical adaptation [19].

Mechanosensors, including SARs, adapt during sustained simulation $[1,3,19,20]$. This is called neural habituation. At present, we do not know its underlying mechanisms. DiCaprio et al. [21] demonstrated an activity-related component of afferents in the Golgi tendon organs of insects that occurs with either electrical or mechanical stimulation. They believed that $\mathrm{Ca}^{2+}$-dependent $\mathrm{K}^{+}$channels generated slowly after hyperpolarization, restricting the generation of action potentials as previously suggested by Erxleben [22]. They added $\mathrm{Ba}^{2+}$ to the solution surrounding tendon organs, thus preventing the influx of $\mathrm{Ca}^{2+}$, and blocked the adaptation of these mecha- 
nosensors. They also demonstrated that high levels of $\mathrm{Ca}^{2+}$ exaggerated adaptation [21].

In this study, we determined the relative importance of the three mechanisms in reducing SAR activity during PEEP application. Clearly, receptor deactivation and neural habituation are major mechanisms while mechanical adaptation plays a minor role in decreased SAR activity. When all the units were included $(\mathrm{n}=18)$, SAR activity decreased from 86.2 to $44 \mathrm{imp} / \mathrm{s}$ during the $20-\mathrm{min}$ PEEP application. Removing the 4 deactivated units ( $\mathrm{n}=$ 14), SAR activity decreased from 80.5 to $56.5 \mathrm{imp} / \mathrm{s}$. The difference between the two resultant values, i.e. 42.2 $24=18.2 \mathrm{imp} / \mathrm{s}$ was caused by receptor deactivation, accounting for $43.1 \%(18.2 \div 42.2 \times 100)$ of the total SAR decrease during the PEEP application. Therefore, neural habituation and mechanical adaptation together accounted for $56.9 \%$ (i.e. $100-43.1$ ). The application of 10 $\mathrm{cm} \mathrm{H}_{2} \mathrm{O}$ PEEP increased peak airway pressure from 9.3 to $32.7 \mathrm{~cm} \mathrm{H}_{2} \mathrm{O}$ and receptor activity from 35.7 to 80.5 $\mathrm{imp} / \mathrm{s}$. Assuming a linear relationship, this gives a 1.9-imp/s increase per $\mathrm{cm} \mathrm{H}_{2} \mathrm{O}$. For a 3.3- $\mathrm{cm} \mathrm{H}_{2} \mathrm{O}$ pressure difference between the start and end of PEEP application, the receptor activity would decrease by $6.3 \mathrm{imp} / \mathrm{s}$. Since neural habituation and mechanical adaptation accounted for $56.9 \%$ of the total decrease in SAR activity, mechanical adaptation would account for $14.9 \%$ [6.3 $\div$ $(80.5-56.5) \times 56.9 \%$ ] and neural habituation for $42 \%$. In fact, total SAR input in relation to the airway pressure is nonlinear. Many SARs do not increase as much at high pressure, thus mechanical adaptation should be $<14.9 \%$.

The SAR is stimulated when airways where the receptor is located are stretched. The SAR activity is determined not only by external stimuli (stretch of the airway by pressure), but also by its internal properties (e.g. its sensitivity to stretch and threshold for activation) [3]. An increased PEEP (as CPAP application in the clinical setting) would, of course, simultaneously increase airway pressure, thereby stimulating the SAR. The stimulus can be the peak pressure, the integrated pressure, the pressure profile or a combination of these. We believe that stretch of the airway will activate the SAR and increase its metabolism. In our previous studies, we found the more active the SARs, the easier they were to deactivate [13]. Furthermore, lung inflation-induced SAR deactivation was more closely associated with receptor activity than the airway pressure. Priming the airway with a lower level of constant pressure (like PEEP application) keeps the SAR active and promotes its deactivation [13].

It is desirable to apply the knowledge obtained from animal studies to assist clinical practice. Haxhiu et al.
[10] demonstrated that after 1 min of lung inflation by PEEP, the expiratory time gradually returns to baseline values. Such a progressive diminution of response can be explained by the gradual decline of SAR activity. Distention of the airway initially leads to increased SAR signals, resulting in decreased phrenic nerve activity [9] and, in turn, prolonged expiration [10]. In COPD patients, the HBR was weakened [8]. Possibly, the intrinsic PEEP present for years in COPD patients leads to an attenuation of SAR responses to elevated pressures. The HBR can be a protective mechanism to reduce lung overdistention and resultant volutrauma. There are numerous iatrogenic (e.g. mechanical ventilation) and pathological (e.g. COPD) processes that distend the lungs; SARs play a role here. With prolonged stimulation, SAR activity gradually returns toward baseline, blunting the reflex response and leading to a relatively normal inspiratory and expiratory time. This mechanism may explain why COPD patients have a minimally prolonged expiratory time. Waters et al. [23] demonstrated that $25 \%$ of children receiving CPAP titration developed hypoventilation at high pressures, a finding long observed in both pediatric and adult patients. Excessive BPAP or CPAP in obstructive sleep apnea therapy could actually increase apneic episodes, counteracting treatment benefits. Some patients with apparent obstructive sleep apnea-hypopnea syndrome experience an elimination of obstructive events but an emergence of central apnea after exposure to CPAP or BPAP [24], i.e. the so-called complex sleep apnea syndrome. Fortunately, a decreased SAR input diminishes the respiratory inhibition and prevents potential hypoxia.

It is also important to consider the impact of the HBR on ICU patients who are being weaned by means of pressure support. The rapid shallow breathing index (RSBI = $\mathrm{f} / \mathrm{Vt}$; respiratory rate in breaths/min divided by tidal volume in liters) is often used to predict successful extubation. High airway pressure could prolong expiratory time and decrease respiratory frequency, creating a misleading and false sense of security for extubating. Since high airway pressures may cause apneic episodes through the HBR, the question is raised whether patients with compromised pulmonary function would be better-served by a gradual application of positive pressure support similar to that applied during sleep-laboratory titration as opposed to a rapid application. If, indeed, time should be allowed for adaptation, as demonstrated in our study, this could have important ramifications for the application of noninvasive mechanical ventilation; this needs to be followed up in clinical trials. 
One of the limitations of this study is our use of an animal model. Although this was necessary for studying the underlying mechanisms, it means that a direct translation of the results to humans is not feasible. In addition, we employed open-chest preparation. This differs from the closed-chest procedure in that it exposes the lung directly to the atmosphere, which may affect the SAR behavior. However, several investigators show similar receptor activities in open- versus closed-chest preparations [25-27]. Since the difference was quantitative but not qualitative, our study did provide potential mechanisms of SAR behavior during PEEP application.

\section{Conclusions}

SARs may be deactivated under high-pressure, cyclic ventilation. High PEEP vigorously stimulated SARs, but the total SAR input gradually returned towards the baseline via multiple mechanisms including receptor deactivation, neural habituation and mechanical adaptation.

\section{Acknowledgements}

This work was supported by a grant from VA Merit Review (PULM-029-10S).

\section{Financial Disclosure and Conflicts of Interest}

No conflict of interest exists for any authors.

\section{References}

1 Coleridge: Reflexes evoked from tracheobronchial tree and lungs; in Handbook of Physiology, Section 3: The Respiratory System. Washington, American Physiological Society, 1986, pp 395-430.

$\checkmark 2$ Lee LY, Shuei LY, Gu Q, Chung E, Ho CY: Functional morphology and physiological properties of bronchopulmonary C-fiber afferents. Anat Rec A Discov Mol Cell Evol Biol 2003;270:17-24.

-3 Yu J: Airway mechanosensors. Respir Physiol Neurobiol 2005; 148:217-243.

$\checkmark 4$ Guz A: Hering and Breuer revisited in humans: an invasive study before the days of ethics committees. Am J Respir Crit Care Med 2001;164:1110-1111.

$\checkmark 5$ Ayers L, Stoewhas AC, Ferry B, Stradling J, Kohler M: Elevated levels of endothelial cellderived microparticles following short-term withdrawal of continuous positive airway pressure in patients with obstructive sleep apnea: data from a randomized controlled trial. Respiration 2013;85:478-485.

-6 Galetke W, Puzzo L, Priegnitz C, Anduleit N, Randerath WJ: Long-term therapy with continuous positive airway pressure in obstructive sleep apnea: adherence, side effects and predictors of withdrawal - a 'real-life' study. Respiration 2011;82:155-161.

7 Gattinoni L, Pelosi P, Crotti S, Valenza F: Effects of positive end-expiratory pressure on regional distribution of tidal volume and recruitment in adult respiratory distress syndrome. Am J Respir Crit Care Med 1995;151: 1807-1814.

-8 Tryfon S, Kontakiotis T, Mavrofridis E, Patakas D: Hering-Breuer reflex in normal adults and in patients with chronic obstructive pul- monary disease and interstitial fibrosis. Respiration 2001;68:140-144.

-9 Stanley NN, Altose MD, Cherniack NS, Fishman AP: Changes in strength of lung inflation reflex during prolonged inflation. J Appl Physiol 1975;38:474-480.

10 Haxhiu MA, van Lunteren E, Cherniack NS: Responses of upper-airway dilating muscles and diaphragm activity to end-expiratory pressure loading in anesthetized dogs. Respiration 1989;56:1-10.

11 Yu J, Pisarri TE, Coleridge JC, Coleridge HM: Response of slowly adapting pulmonary stretch receptors to reduced lung compliance. J Appl Physiol 1991;71:425-431.

12 Yu J: Spectrum of myelinated pulmonary afferents. Am J Physiol Regul Integr Comp Physiol 2000;279:R2142-R2148.

13 Guardiola J, Proctor M, Li H, Punnakkattu R, Lin S, Yu J: Airway mechanoreceptor deactivation. J Appl Physiol 2007;103:600-607.

14 Adrian ED: Afferent impulses in the vagus and their effect on respiration. J Physiol 1933; 79:332-358.

-15 Farber JP, Fisher JT, Sant'ambrogio G: Distribution and discharge properties of airway receptors in the opossum, Didelphis marsupialis. Am J Physiol 1983;245:R209R214.

16 Matsumoto S, Takahashi T, Tanimoto T, Saiki C, Takeda M, Ojima K: Excitatory mechanism of veratridine on slowly adapting pulmonary stretch receptors in anesthetized rabbits. Life Sci 1998;63:1431-1437.

17 Winner E, Zhang JW, Proctor M, Yu J: Ouabain stimulates slowly adapting pulmonary stretch receptors. Acta Physiol Sinica 2005;57: 689-695.
18 Punnakkattu R, Zhang JW, Guardiola J, Cheng Z, Gozal D, Yu J: Baroreceptor inactivation by over-excitation. FASEB J 2004; A103LB500.

19 Sant'ambrogio G: Information arising from the tracheobronchial tree of mammals. Physiol Rev 1982;62:531-569.

20 Widdicombe JG: Airway receptors. Respir Physiol 2001;125:3-15.

21 DiCaprio RA, Wolf H, Buschges A: Activitydependent sensitivity of proprioceptive sensory neurons in the stick insect femoral chordotonal organ. J Neurophysiol 2002;88:23872398.

22 Erxleben CF: Calcium influx through stretchactivated cation channels mediates adaptation by potassium current activation. Neuroreport 1993;4:616-618.

23 Waters KA, Everett FM, Bruderer JW, Sullivan CE: Obstructive sleep apnea: the use of nasal CPAP in 80 children. Am J Respir Crit Care Med 1995;152:780-785.

24 Morgenthaler TI, Kagramanov V, Hanak V, Decker PA: Complex sleep apnea syndrome: is it a unique clinical syndrome? Sleep 2006; 29:1203-1209.

25 Bergren DR, Peterson DF: Identification of vagal sensory receptors in the rat lung: are there subtypes of slowly adapting receptors? J Physiol 1993;464:681-698.

26 Tsubone H: Characteristics of vagal afferent activity in rats: three types of pulmonary receptors responding to collapse, inflation, and deflation of the lung. Exp Neurol 1986;92: 541-552.

27 Wei JY, Shen E: Vagal expiratory afferent discharges during spontaneous breathing. Brain Res 1985;335:213-219. 